\title{
LA IDENTIDAD PERSONAL, CULTURAL Y VOCACIONAL
}

DOI: https://doi.org/10.52039/seminarios.v61i213.189

PINA DEL CORE*

PREMISA

La reflexión sobre la identidad personal y cultural en una época de globalización y fragmentación, de integración y desintegración, no es nueva, ciertamente. Ante el proceso de globalización, los estudiosos del problema han tenido que constatar que las profundas transformaciones, promovidas por las características de este nuevo paradigma, no afectan sólo a la vida social, sino que están promoviendo una profunda reestructuración -diríase que casi completa- de nuestra forma de vivir. «Resulta erróneo pensar -comenta el escritor Anthony Giddens- que la globalización se refiere sólo a los grandes sistemas, como el orden financiero mundial: no toca sólo lo que está 'fuera', remoto y distante del individuo, sino que es también un fenómeno interno, que influye en los aspectos íntimos y personales de nuestra vida» ${ }^{1}$; «no es un incidente en nuestras vidas de siempre. Es el cambio de las condiciones mismas de nuestra existencia. Es el modo como vivimos hoy» ${ }^{2}$.

Además, hace ya bastante tiempo que la problemática sobre cuánto influye la globalización en los ya laboriosos procesos que connotan el crecimiento de cada persona en su camino de individuación y de elaboración de su propia identidad personal y cultural centra la atención de diversas disciplinas, desde la sociología a la antropología cultural, desde la psicología a la pedagogía. Si la interdependencia a nivel planetario, la movilidad y la intensificación de las interacciones sociales mundiales, el desmoronarse de las relaciones interpersonales reales al dar ventaja a las relaciones virtuales, la compresión o compactación del tiempo y del espacio, de los estilos de vida y de las culturas, son las coordenadas dentro de las cuales desarrollan su vida y crecen las nuevas generaciones, dentro de las

* Pina Del Core es profesora de Psicología del desarrollo y vicepresidenta de la Pontificia Facultad de Ciencias de la Educación de Roma.

1. Giddens, A., II mondo che cambia. Come la globalizzazione ridisegna la nostra vita, Bologna 2000, 24. «La globalización está reestructurando nuestro modo de vivir, y de forma muy profunda. La globalización influye no sólo en los acontecimientos a escala mundial, sino en la vida cotidiana» (Ibid.13).

2. Ibid, 31. 
cuales construyen su propia identidad y realizan sus opciones de vida. Por todo esto, resulta imprescindible reflexionar seriamente sobre la influencia que tales fenómenos, ahora ya imparables, dejan sentir en los procesos de formación, desde el descubrimiento de la propia vocación hasta la consolidación de la propia identidad vocacional y carismática.

Parafraseando al pensador Anthony Giddens podríamos decir que la globalización está volviendo a diseñar nuestra vida y la vida religiosa misma, por sus repercusiones significativas en las actitudes éticas, en el modo de vivir el tiempo y la proyectualidad, la corporeidad y la sexualidad, las relaciones y, por tanto, la identidad misma.

El redescubrimiento de la diversidad cultural e identificatoria, los peligros y las degeneraciones del multiculturalismo, la dificultad de conciliar la diversidad étnica, cultural y lingüística con la unidad sociopolítica de las naciones o con la unidad comunional de un Instituto religioso, constituyen otras tantas instancias que interpelan y que es necesario afrontar con equilibrio y creatividad, teniendo en cuenta las repercusiones tanto en las personas como en las comunidades y en el carisma.

\section{Globalización y vida consagrada}

En efecto, el proceso de globalización genera la homologación de las culturas, apaga las particularidades y penaliza las diversidades, poniendo en crisis las identidades personales y culturales, creando complejos de inferioridad /superioridad entre las culturas, al mismo tiempo que exalta el poder y el monopolio de la cultura de la comunicación, la cual se encuentra en manos de unos pocos detentadores. Pensemos en los efectos de ese proceso en el ámbito de la vida consagrada, concretamente en nuestros Institutos, que son cada vez más multiculturales y cuya variedad de nacionalidades hace que se encuentren más y más afectados por la globalización.

Hoy, sin duda, estamos viviendo un momento de cambio, quizás nunca registrado en la historia, que ha provocado en los países occidentales una profunda crisis en el modo de pensarnos a nosotros mismos y nuestra propia identidad, en el modo de percibir y vivir la realidad, hasta el punto de modificar casi radicalmente los paradigmas que rigen la cultura y las culturas. $Y$ todas esas transformaciones han tocado muy de cerca también a la vida religiosa, induciendo procesos que llevan a repensar no sólo el estilo de vida, sino incluso la propia identidad de la institución.

En el contexto de una cultura de globalización, que conlleva exigencias de pluricentrismo y de apertura intercultural, la identidad compleja de la vida religiosa exige un profundo proceso de inculturación que, si por un lado implica poner en el centro la alteridad de las diferencias y de las culturas, al mismo tiempo reporta a lo esencial del ser, a una identidad dinámica que se confronta y se confía. 
"Identidad, cultura y vocación» se convierte, por consiguiente, en uno de los temas decisivos para el futuro de la formación en la vida consagrada, así como para la misma evangelización. El razonamiento, aun estando orientado hacia indicaciones de carácter operativo, se presenta, desde el punto de vista teórico, bastante complejo, porque toca problemas que no son en absoluto periféricos, sino coyunturales, en especial si se tiene en cuenta la estrechísima interconexión que hay entre los términos puestos en relación. En qué proporción las identidades, de las personas y de las instituciones, están plasmadas, transformadas, mejoradas o empobrecidas por la cultura y las culturas, es un dato que se percibe inmediatamente, aun partiendo sólo de la experiencia. En el fondo de estas grandes transformaciones culturales dirigidas y aceleradas por el fenómeno de la globalización, hay que repensar y re-comprender la identidad de las personas, en masculino y en femenino, y la identidad misma de la vida religiosa, para formular recorridos formativos adecuados a las nuevas emergencias y a las nuevas necesidades provenientes de los cambios de la situación sobre todo la de los jóvenes.

En una sociedad dominada por la ciencia, por la tecnología, por la realidad virtual, por modelos estándares de comportamientos y de estilos de vida, los esquemas interpretativos del camino de vida de los religiosos se presentan inciertos, ambivalentes y poco comprensibles desde las lógicas habituales, especialmente por parte de las nuevas generaciones. Además, es precisamente en el tiempo de cambio, tal como sucede en cualquier proceso de crecimiento, cuando la vida religiosa puede encontrar en sí misma nuevos modelos de vida y de misión, nuevas claves de lectura de sí misma y de la historia. En efecto, son muchos los intentos que se están haciendo de leer las perspectivas futuras a partir de los nuevos fenómenos socioculturales, políticos y económicos, y de las nuevas instancias que provienen del interior de la propia vida consagrada, como la inculturación del carisma, la interculturalidad y la internacionalidad, la misión evangelizadora en relación con la cultura de la comunicación y con los desafíos que la misma conlleva.

\section{¿Qué formación?}

Así pues, es necesario que la formación se confronte con los cambios culturales y las perspectivas de fondo que se abren ante nosotros. En efecto, los nuevos paradigmas culturales ponen necesariamente en tela de juicio los sistemas de formación inicial y permanente, y piden repensar de una manera global los modelos y los procesos formativos.

Echando una mirada a los cambios tecnológicos y culturales provenientes de la globalización, a lo invasivo de las nuevas tecnologías comunicativas, al incremento de informaciones y de nuevos conocimientos, pero también al emerger de nuevos saberes, nos preguntamos: ¿Cómo hacer frente a todo eso, a los 
éxitos de la revolución tecnológica y al vuelco de los tradicionales modelos de conocimiento y de transmisión del saber y de los valores? ¿Cómo situarse frente a las nuevas formas de convivencia, de estilos de vida y de relaciones cada vez más amenazadas por la invasión y la fascinación de la realidad virtual? No es cuestión de poca monta.

Impartir formación en un mundo que cambia continuamente, en un tiempo de subjetividad y de fragmentación, no resulta en absoluto fácil. Se advierte la exigencia de nuevos indicadores y de nuevos modelos que ayuden en el camino más bien complejo, frecuentemente inédito para la vida religiosa, y especialmente para la femenina.

Establecer itinerarios formativos, sincronizados y sintonizados con el cambio, bajo el signo de la movilidad, de la novedad y de la precariedad/provisionalidad, constituye una empresa verdaderamente ardua, tanto para la Iglesia y las instituciones educativas, como para la vida religiosa, que hasta hace alguna década se movían con paradigmas de estabilidad o de fijeza más que con el dinamismo de una situación en continua y rápida evolución. En efecto, muchos motivos de la crisis actual se pueden remontar a la dificultad de encontrar modelos, aun mentales, para vivir en la lógica de los procesos y de la precariedad de la condición humana. La crisis está presente en todo cambio, y hoy nos encontramos con el cambio hacia modelos nuevos e inéditos, a senderos todavía por explorar que esperan personas valientes que no temen la ansiedad de la incertidumbre que el cambio provoca.

\section{Recorridos «nuevos» de búsqueda}

En ese sentido, la formación es un desafío de los más serios para los años venideros, un 'taller de obra' que pide la necesidad de encontrar 'recorridos nuevos' de búsqueda y de realización.

Uno de estos recorridos 'nuevos', quizá todavía 'inexplorados' por una reflexión sistemática y articulada, es precisamente la relación identidad-cultura-vocación. La temática de la identidad en relación con la cultura y la vocación, precisamente en la encrucijada de múltiples expectativas y perspectivas, puede ofrecer un aportación significativa a la elaboración de nuevas síntesis. Éstas, traducidas en términos operativos, podrán facilitar el proceso de inculturación del carisma y de la formación de identidades vocacionales capaces de afrontar el cambio, y de hacerlo con el gozo de ser lo que estamos llamados a ser en el contexto actual que representan nuestras sociedades. A esa identidad se refieren de nuevo algunas cuestiones de fondo que son cruciales, como las de la identidad carismática, de la inculturación y de la interculturalidad.

La cuestión de la identidad carismática es central. Repensar la identidad y su relación con el carisma en un contexto universal, pero también particular, significa afrontar necesariamente el tema de la fidelidad $y$, por consiguiente, de 
la respuesta que a nivel personal, comunitario y como Instituto deberíamos dar para retornar a las propias raíces carismáticas no como parte de un pasado, aunque sin duda glorioso, sino como utopía del futuro. Es decir, se trata de alimentar una fidelidad que intenta volver a situarse en el corazón de la historia con sus instancias y sus retos.

$Y$ todo esto conlleva, no cabe duda, la valentía de preguntarse continuamente acerca de la 'dirección': ¿A dónde vamos? ¿Por qué y para qué formarse y formar? Seguir conservando o administrando el statu quo no es posible; puede convertirse en un simple restañar, con lo que la renovación invocada y la refundación 'soñada' corren el peligro de transformarse en pura adaptación que no logra mirar hacia adelante.

La flexibilidad y la capacidad de vivir el cambio como respuesta de fidelidad más al futuro que al pasado se hacen cada vez más raras. Se requieren personalidades abiertas, flexibles y suficientemente estables para afrontar las innegables crisis provenientes de la reestructuración y de los muchos éxodos requeridos para vivir la propia vocación, aquí y ahora, en la historia. De hecho, no pocos problemas, aun personales, hay que remontarlos a la incertidumbre de la transición histórica que estamos atravesando, en la que pluralismo cultural y globalización han cuestionado la identidad, haciendo cada vez más problemáticos los procesos de formación de la identidad personal y cultural, sobre todo en los jóvenes.

El don de nuevas generaciones que, culturalmente diversas, entran a formar parte de nuestras familias religiosas, si por un lado constituye un reto que atañe a todo -espiritualidad, formación, comunidad, misión, gobierno, economía- es también un compromiso que hay que construir por entero. Las nuevas vocaciones traen consigo una nueva sensibilidad cultural y étnica, y la identidad carismática se halla sometida necesariamente a procesos de discernimiento y de cambio.

El desarrollo y la continuidad del carisma en el tiempo están vinculados con el secreto de una eficaz transmisión generacional de los valores vocacionales en las comunidades locales y a través de procesos identificativos generadores de entusiasmo y de pertenencia. Eso supone, sobre todo en el ámbito de la formación permanente, aprender a elaborar continuamente la propia identidad vocacional, mediante procesos de maduración y reapropiación en los diversos contextos culturales.

El proceso de inculturación, auténtico kairós para la Iglesia y para el Instituto, es otro aspecto nuclear. La compleja y ardua tarea de la inculturación, como la llama el Papa en Vita Consecrata, se va realizando muy lentamente y no siempre con modalidades eficaces y coherentes para la fecundidad del carisma ${ }^{3}$. No faltan oportunidades y riesgos; de ahí la urgencia de una reflexión seria y de una

3. Juan Pablo II, Exhortación Apostólica post-sinodal Vita Consecrata, 79b. 
comprobación constante de la aptitud de búsqueda y discernimiento. Se trata de un proceso ineludible porque de él depende la capacidad de renovación de la vida religiosa y la fidelidad creativa al carisma. Toda la formación en sus recorridos y procesos tiene como perspectiva el compromiso de asumir el dinamismo profético del carisma para traducir la intuición original de los fundadores en la realidad concreta en que vivimos y actuamos.

La fidelidad al carisma ha de convertirse en capacidad de acogida de una 'entrega' que continuamente se enriquece mediante la vivencia personal y comunitaria y la confrontación con las instancias evangélicas y culturales. La experiencia vocacional vivida con alegría y en plenitud por las generaciones anteriores, hecha visible por una identidad de vida clara y significativa, genera así renuevos que, a su vez, seguirán elaborando nuevos recorridos identificativos, "con fidelidad a la gracia de la vocación recibida y con atención a la historia»", cada vez más con el color y el rostro de cada cultura y de los contextos diversificados en que se vive.

El nudo de la interculturalidad en nuestras comunidades. La tupida red de sociedades multiétnicas, multiculturales y multirreligiosas que se ha formado en el mundo actual, es ahora ya un proceso imparable que reclama el desarrollo de inéditos módulos de convivencia y de un nuevo modo de educación y de formación, si bien en el plano de los procesos subjetivos la lógica de la 'monocultura' tarda en desaparecer. Bastaría pensar en el retorno de fuertes tensiones de identidad, de nostalgia de la pertenencia, de la pequeña patria, de las culturas locales, que está haciendo cada vez más difícil la tolerancia mutua y la convivencia entre poblaciones de la misma área cultural, pero marcadas por diferentes tradiciones, valores y costumbres.

Una de las objeciones más estimulantes en este campo es la de que el diálogo intercultural pueda dañar una a una las identidades culturales, que el pluralismo lleve al relativismo o a la pérdida de los sistemas de significado y de valores. Pluralismo y diálogo no implican la pérdida de la identidad, pero abren a la alteridad y, por consiguiente, a la riqueza de las diversidades. Eso exige itinerarios de educación intercultural que propicien el reconocimiento y la reapropiación de la identidad propia para saber interactuar con otras identidades.

La dimensión planetaria en que estamos inmersos abre a una «mundialidad» cada vez más ampliada cuyas expresiones más elocuentes son la internacionalización y la interculturalidad. Y esto no es ya sólo «utopía», sino que constituye una llamada y una tarea para las sociedades civiles, y también para la propia vida consagrada.

La comunidad religiosa, pues, puede hacerse profecía, si es capaz de vivir y testimoniar la utopía de una cultura e identidad planetarias, la posibilidad del encuentro y del diálogo entre naciones y culturas diversas en una pacífica

4. Cf. Istituto Figlie di Maria Ausiliatrice, Nei solchi dell'Alleanza, Leumann, Torino 2000, 149. 
convivencia de pueblos y religiones. Toda comunidad que acepta el desafío de la interculturalidad se transforma así en paradigma de comunión, en el que es posible conjugar juntos especificidad y universalidad, mundialidad y localismo, identidad y alteridad, igualdad y diferencia, unidad y diversidad.

Ante cuestiones tales de un espesor histórico-cultural multiforme y dinámico, punto nuclear es la formación. En efecto, el compromiso por la formación es una estrategia prioritaria, clave de solución para los nuevos retos lanzados a la vida consagrada. El interrogante que nos acompaña e inquieta en este tiempo es: ¿qué futuro para la formación?

La experiencia de estos años nos estimula a preguntarnos seriamente si los modelos formativos todavía existentes son capaces de responder a tales interpelaciones o si, por el contrario, es necesario un repensar la situación y un salto de cualidad. ¿Cómo se vive la situación de internacionalidad e interculturalidad de nuestras comunidades, y cómo es administrada para que sea realmente «formativa», es decir, para que ayude a madurar «identidades» capaces de asumir la cultura propia e integrarse con otras culturas distintas, sin perder las propias raíces, enriqueciéndose con el aporte valorativo proveniente del encuentro con la diversidad?

Las vocaciones provenientes de los diferentes contextos culturales, naciones o etnias ¿cómo asumen su propia identidad cultural a lo largo del camino de formación de la identidad vocacional? ¿Cuáles son las dificultades o los problemas más frecuentes en nuestras comunidades, de ahora en adelante cada vez más multiculturales y multiétnicas? ¿Y cuáles podrían ser los recorridos formativos que hacen posible todo eso?

\section{Perspectiva del razonamiento}

Repensar la identidad y su relación con la vocación en un mundo globalizado requiere un diálogo con las ciencias humanas, cuya contribución puede iluminar los dinamismos de la persona y de la sociedad en la que está llamada a vivir su vocación; pero sobre todo para la comprensión de la cultura actual y de las diversas culturas en las que habrá de encarnar el propio carisma. En el fondo, la vida consagrada se presenta como una identidad de vida, como una «propuesta de un camino que cada persona ha de recorrer, si bien según modalidades diferentes, para llegar a una identidad terminada y a una plenitud de sentido de la vida propia» ${ }^{5}$.

Mi reflexión sobre el tema, aunque se mueve en una perspectiva de carácter psicológico y antropológico-existencial, opta conscientemente por situarse también en una línea pedagógico-formativa, con la intención de ofrecer elementos

5. Pinkus, L., Psicodinamica della vita consacrata, Leumann (Torino) 2000. Ver también: Tacconi, G., Alla ricerca di nuove identità. Formazione e organizzazione nelle comunità religiose di vita apostolica attiva nel tempo della crisi, Leumann (Torino) 2001. 
que permitan individuar los caminos formativos que la persona y las comunidades han de recorrer para armonizar identidad y cultura, en la gozosa tarea de realizar su propia vocación.

\section{IDENTIDAD Y CULTURA: DINÁMICA DE INTERACCIÓN}

La multiplicación de los intercambios, la globalización de los mercados y de las comunicaciones han puesto en el centro de la educación la cuestión de las identidades individuales y colectivas, de las relaciones entre hombres y mujeres de diversas culturas, de la capacidad de vivir juntos en el mutuo respeto de la libertad de cada cual y, sobre todo, la cuestión de la modalidad de gestión de la violencia y de la resolución de los conflictos - de las relaciones de fuerza- entre individuos, grupos e instituciones. Pero, en primer lugar, han entrado en crisis las concepciones tradicionales de la identidad, hasta el punto de que la cuestión de la identidad, tanto individual como colectiva, ha pasado a ser ya ahora una de las más urgentes y más complejas de resolver ${ }^{6}$.

En semejante contexto, parece que se ha hecho mucho más problemática la identidad y su formación.

De hecho, la identidad personal se construye y se elabora dentro de una cultura que constituye el ambiente y el lugar privilegiado para dar especificidad y «color» a cada persona. La identidad no está dada desde el principio como dotación que se recibe en el nacimiento; representa el resultado laborioso y complejo de una historia personal, construida en el interior de la trama de relaciones interpersonales y de interacciones múltiples con el ambiente, partiendo de la elaboración de los modelos culturales y de las diferentes experiencias de vida.

La identidad, según las recientes conquistas de la psicología, sociología y antropología cultural, ya no es considerada como una entidad o una estructura, como «lo que queda» más allá del fluir de las vicisitudes y las circunstancias, de las actitudes y las experiencias, sino como una realidad construida, buscada, inventada. Tiene carácter de "construcción», que implica un trabajo de diferenciación, es decir, de separación y de asimilación que, sin embargo, se realiza sobre la base de un continuo flujo y cambio ${ }^{7}$.

Para que pueda manifestarse la identidad, es necesario que la persona se vea a sí misma como un todo unitario y aprenda a reconocer su propia y especial diversidad de individuo (proceso de individuación), en un continuo hacerse y deshacerse, «separarse de» y «reconocerse en», o sea, en el reconocerse igual a sí mismo y diverso de los demás, más allá de todas las transformaciones que ponen en crisis tal igualdad y tal diversidad ${ }^{8}$.

6. Cf. Perotti, A., La via obbligata dell'interculturalità, Città di Castello (Perugia) 1994, 18.

7. Cf. Remotiffi, F., Contro l'identità, Bari 1996, 4-10.

8. Cf. Erikson Erik, H., Gioventù e crisi d'identità, Roma 1974, 58. 
Entonces es lícito preguntarse: ¿Cuáles son los procesos de adquisición y construcción de la identidad personal y cultural? ¿Y cuáles los recorridos formativos que favorecen la reapropiación de la identidad personal y el reconocerse en las diferencias (de género, de lengua, de cultura...) contra el riesgo de la homologación y del anonimato?

\section{1. ¿Qué cultura y qué identidad?}

Cuando se habla de 'cultura', nos encontramos ante descripciones muy extensas, tales que coinciden con la gama entera de las actividades humanas, desde las múltiples relaciones entre el hombre y la naturaleza (procurarse y conservar la comida, asegurarse el estar al abrigo de las fuerzas de la naturaleza, los diversos modos con que el hombre domina y controla el ambiente natural) a las interacciones entre semejantes y diversos grupos sociales, entre los sexos, entre ancianos y jóvenes, etc., hasta la organización política y religiosa y las actitudes ante la vida y las valoraciones o visiones del mundo y de la realidad (ética, estética, religión). Esas definiciones tienen el carácter de universalidad (una idea general de la humanidad y de la capacidad de intercambio) que parece contrastar con una modalidad relativista de concebir la cultura como una combinación de diversas culturas y subculturas particulares que pueden llevar a una verdadera localización (localismos, nacionalismos, regionalismos, etnocentrismos, etc.) de la dimensión universal de la cultura9.

«El proceso de globalización sugiere dos imágenes de cultura: la primera imagen implica la extensión fuera de una cultura particular hacia su propio límite, el globo. Culturas heterogéneas se incorporan e integran en una cultura dominante que, al final, abarca el mundo entero. La segunda imagen se refiere a la compresión de las culturas: elementos anteriormente aislados son llevados ahora al contacto y la yuxtaposición. Las culturas se amontonan una sobre otra sin claros principios organizativos, es demasiada la cultura que hay que ordenar y organizar en sistemas coherentes de creencias, en instrumento de orientación y conocimiento práctico» ${ }^{10}$.

Todo eso replantea de forma dramática el problema de la identidad étnica (o etnicidad) que hay que salvaguardar en primer lugar de las amenazas de «cons-

9. En la actual complejidad cultural en la que nos encontramos, el concepto tradicional de cultura, entendido como el conjunto de valores, creencias y prácticas ampliamente compartidas e integradas en una visión unitaria, resulta inadecuado, sobre todo si se parte del presupuesto y prejuicio de la superioridad de la cultura occidental. Según Smith una cultura global no tiene razón de ser, porque no podría garantizar aquello que un grupo social o una comunidad necesita para desarrollar una identidad, lo que es lo mismo que decir el sentido de continuidad, una memoria histórica compartida y el sentido de un destino común. «No hay 'memorias mundiales' que puedan ser utilizadas para unir la humanidad» (Smith, D. A., Towards a Global Culture?, en Featherstone, M., La cultura dislocata. Globalizzazione, postmodernismo, identità, Roma 1998, 180).

10. Featherstone,M., La cultura dislocata 17. 
trucciones mentales» -a menudo de naturaleza ideológica o política- proclives o a homologar o a dividir/separar (nosotros > ellos) aquello que, en cambio, hay que recomponer en unidad.

En efecto, el proceso de enfatización de los rasgos culturales idiosincrásicos (identidad étnica) es peligroso si no se tiene en cuenta la dinámica de cambio a que están sometidas las identidades: un continuo proceso de definición y «reajuste» hacia una ulterior diferenciación de las demás identidades (o de fusión) en el contacto y el intercambio con «lo externo» con otras culturas (interno/externo, identidad/apertura). No es fácil administrar pedagógicamente el armónico equilibrio entre necesidad de identidad/pertenencia y necesidad de apertura a otras culturas, entre educación nacional y educación en la mundialidad. Toda identidad (individual o comunitaria) que sea concebida de forma homogénea y totalizadora es peligrosa o falsa: puede llegar a ser un instrumento en mano de los movimientos ideológicos o políticos que buscan definir la identidad de manera predeterminada, por oposición y exclusión respecto de otros grupos e individuos.

Por tanto, es indispensable repensar la identidad de forma pluralista y dinámica, desde el momento en que condiciona el modo en que las personas y los grupos piensan, se definen en sus semejanzas/diferencias con otros individuos y grupos, y se relacionan.

\section{Identidad cultural y/o identidad étnica: una cuestión controvertida}

Hay una estrecha relación entre cultura e identidad, ya que si, por un lado, no hay persona sin cultura, por otro, no hay cultura sin persona. La identidad personal coincide, pues, de alguna forma con la identidad cultural. Mediante el proceso de inculturación y socialización, la identidad toma la forma que la cultura asume en los sujetos, en los grupos o en las diversas identidades que la componen. De ahí se sigue que cada persona en su obrar actúa según una identidad cultural que adquiere, define, modifica y vuelve a definir a lo largo de un proceso que dura toda la existencia ${ }^{11}$.

El problema de la identidad cultural está alcanzando dimensiones cada vez más amplias no sólo en las sociedades complejas, sino también en las denominadas «simples». La identidad cultural atraviesa hoy una crisis profunda por efecto tanto del proceso de homologación de los medios de comunicación con el creciente desapego de la tradición (memoria histórica escrita y oral), como del proceso de desarraigo debido a la emigración y a la movilidad territorial por buscar trabajo o una patria o por huir de situaciones políticas, económicas y vivideras imposibles (migraciones de los pueblos). Pensemos también en los problemas provenientes de la apertura tecnológica a modelos urbanos y a for-

11. Cf. Di Cristoforo Longo, G., Identità e cultura. Per un'antropologia della reciprocità, Roma 1993, 33-35. 
mas organizativas propias de mánager, cada vez más en la lógica del mercado y del consumismo de sello occidental.

Para salir del atolladero de la crisis es necesario promover procesos formativos que ayuden a redefinir y reelaborar, desde el interior del propio sistema cultural, los rasgos fundamentales de la identidad cultural, librándola de lo que puede obstaculizar su desarrollo. El proceso de reelaboración y redefinición habrá de realizarse dentro del propio contexto cultural y los propios modelos culturales hasta la reapropiación y reinterpretación de los mismos. Solo así podrá desarrollarse una capacidad selectiva que permitirá hacer frente a los demás modelos que llegan y se imponen desde fuera. Crucial en este proceso es, justamente, la inserción de los modelos que llegan del exterior con los modelos propios, internos a la cultura y de los que no se puede prescindir sin perder la identidad.

En este proceso de inculturación y aculturación son posibles diversas soluciones, por ejemplo: la fijación de la identidad o entumecimiento, la identidad negada y la asimilación acrítica de modelos culturales externos, la oscilación entre modelos culturales conflictivos a veces, la síntesis y la integración ${ }^{12}$.

Pero muy a menudo se cae en formas de hibridismo y sincretismo de mala aleación, fruto de superposición o asimilación de diversos modelos; lo cual solo provoca confusión de identidad, con todas las ambivalencias y conflictos que eso supone.

Una reflexión aparte hay que reservarla al concepto de identidad étnica, asociada con frecuencia a la idea de formas de existencia «primitiva» $\mathrm{o}$ «premoderna», o bien entendida como un dato natural que mezcla individuos del mismo origen, lengua y religión, habitantes de un mismo territorio y poseedores de ciertas tradiciones que los caracterizan. Casi siempre se funda en una concepción errada de etnia o etnicidad, que lleva fácilmente a reivindicaciones y conflictos entre grupos diferentes y contrapuestos ${ }^{13}$.

La identidad étnica se describe como un componente de la identidad social que proviene de pertenecer a un grupo étnico. Retomando el concepto de identidad social de Tajfel (1982), «la identidad étnica se puede definir como la parte de la imagen de sí que nace de la consciencia de ser miembro de un particular grupo étnico, unida al valor y al significado emotivo atribuido a esa pertenencia». La identidad étnica o la etnicidad, en cuanto provenientes del sentimiento de pertenecer a un grupo étnico, son «'definiciones del sí y/o del otro colectivos' que casi siempre tienen sus propias raíces en relaciones de fuerza entre grupos unidos alrededor de intereses específicos» ${ }^{14}$.

12. Cf. algunos estudios ya clásicos de Sciolla, L. (ed.), Identità, Torino 1983; Levi-Strauss, C. G., L'identità, Palermo 1996. También un estudio más reciente que aplica estos parámetros teóricos a los jóvenes del Sur: D'Agostino, F., Giovani in transizione tra identità culturale e sviluppo. Ricerca sulla condizione giovanile in una provincia del Meridione, Milano 1990.

13. Fabietti, U., L'identità etnica, Roma 1998, 13-24.

14. Ibid. 14 . 
La experiencia de pertenencia a un grupo (étnico-territorial) o a una categoría social (joven/adulto, hombre/mujer, estudiante/trabajador, etc.) permite, en el sentido de que puede facilitar o bien obstaculizar, el proceso de elaboración de la propia imagen de sí, hasta llegar a la definición del sí y/o del otro colectivo ${ }^{15}$. Pensemos en el reflejo positivo o negativo que puede tener en la estima de sí o en la capacidad de afrontar las relaciones con la diversidad. Efectivamente, la identidad étnica se adquiere mediante un proceso de confrontación que activa valoraciones y lleva a definir, tanto la posición del propio grupo dentro del contexto social, como el significado que toma la pertenencia a tal grupo dentro del más general concepto de sí.

Sin embargo, es preciso recordar que, si las personas no pueden elegir el propio grupo étnico en el que han nacido, siempre se puede cambiar el significado que atribuyen a su pertenencia, así como el papel que ésta desempeña en la definición de la propia identidad. En efecto, si a nivel evolutivo la identidad se construye sobre la base del proceso de identificación, también la identidad étnica se elabora partiendo de la identificación étnica, la cual es el resultado de un lento proceso subjetivo, a lo largo del cual se prescinde de las pertenencias objetivas de la persona. Efectivamente, se puede comprobar que, a niveles diversos, cualquier persona perteneciente a una minoría étnica podría enfatizar, esconder, camuflar o incluso rehusar su propia etnicidad, a lo mejor para tomar otras identidades sociales y/o religiosas ${ }^{16}$.

\section{3. ¿Qué procesos de reelaboración?}

Un primer proceso, reconocido universalmente como fundamental, es la identificación, es decir, el sentimiento de afirmación, de pertenencia y de valoración del grupo étnico-territorial al que pertenecen los sujetos. Los indicadores de este componente son: el orgullo en relación con ese grupo, la importancia dada a tal pertenencia y su coparticipación (cercanía) de sus tradiciones culturales.

Otro proceso es la exploración, o sea, la actividad de búsqueda y valoración de las posibles alternativas identificativas, mediante una 'inmersión' en la propia cultura o mediante actividades de variado tipo que llevan a la comprensión y al aprecio de la propia etnicidad. Eso incluye tanto una exploración-conocimiento de las características del propio grupo de pertenencia como una exploración-conocimiento de las características de grupos étnicos de no pertenencia. Hay además otro proceso, denominado el compromiso, que toma en consideración la importancia que la pertenencia étnico-territorial reviste para la elaboración de la imagen de sí.

15. Cf. Pollini, G., Appartenenza e identità. Analisi sociologica dei modelli di appartenenza sociale, Milano 1987, 98

16. Cf. Liebkindn, K., Ethnic identity. Challenging the boundaries of social psychology, en Breakwell, G. M. (ed), Social Psychology of identity and Self-Concept, London 1992, 147-186. 
Junto a estos procesos no se puede descuidar la confrontación social y cultural con los demás grupos. Un componente esencial, que funciona como indicador de análisis, viene dado por las actitudes de favor o disfavor ante las relaciones con personas pertenecientes a otros grupos étnico-territoriales.

Otra serie de procesos se refiere, en cambio, a las modalidades de integración que la persona pone en práctica en el momento en que se inserta en el contexto de otras culturas o se inmerge cada vez más en la cultura de su propia época:

- La asimilación, mediante el cual se tiende a privilegiar la cultura que acoge y no la de origen, y eso puede facilitar la aculturación y la integración (frecuente es el bi-culturalismo). Pero, según este cometido, el individuo tendería a adecuarse a las expectativas del ambiente cultural en que debe insertarse. La expectativa, a veces exagerada y fruto del «prejuicio» que más condiciona es la de que todos los extranjeros, o en todo caso los que provienen de una cultura diversa, olviden su pertenencia propia y su cultura propia, aprendan a hablar la lengua del lugar y se hagan como los demás. El peligro es perder todo color y especificidad con tal de «sobrevivir» en el impacto con los demás.

-La integración: si a la sociedad se la imagina como algo culturalmente homogéneo, como el resultado de la adaptación de los individuos «diversos» y del cambio de su modo de vivir y de pensar tanto cuanto basta para sentirse a gusto con el estilo de vida del ambiente cultural en que se insertan, nace la llamada a no pretender el abandono total de su propia cultura o de su propia identidad étnica, sino a tolerar las diferencias entre las culturas.

- La separación es otro proceso dinámico, que se sitúa en el punto opuesto a los dos primeros, dado que se privilegia la pertenencia a la cultura de origen y, por consiguiente, el recién llegado se pone en posición de marginalidad. El peligro más frecuente para este tipo de proceso lo causa el hecho de que la persona o el grupo se cierran en una especie de aislamiento que no sólo empobrece en el plano cultural, afectivo y relacional, sino que puede llevar también a conflictos (nosotros contra los demás) destructivos seguramente.

Sin embargo, es preciso preguntarse: ¿Qué integración? ¿Qué interacción? Para evitar el riesgo de confundir la integración con pseudoformas de asimilación y terminar después negándola mediante la separación, debemos determinar modalidades de integración que salvaguarden el respeto de la diversidad y, a la vez, garanticen el diálogo y la comunión.

Los estudios y las investigaciones realizadas hasta el momento han evidenciado, además del carácter interactivo y dinámico de la identidad, el papel del otro en la representación de la identidad cultural. Hay una especificidad colectiva constituida por rasgos distintivos y significativos, que, aun conservando la propia originalidad, inevitablemente en la interacción se modifican y transforman. Es decir, en el contacto con otras culturas se produce una reorganización de los 
rasgos distintivos identificadores que no es tan consabida. En efecto, no siempre se llega a hacerse cargo de las diversidades: de hecho se las podría rechazar o aceptar acríticamente homologándose.

Por lo tanto, para que no salten mecanismos de identificación proyectiva o de valoración selectiva, es necesario estar atentos a crear condiciones de tiempo y espacio para que las personas aprendan un conjunto de reglas, códigos y símbolos en virtud de los cuales se puedan orientar en el 'nuevo espacio' y en el 'nuevo tiempo', y se puedan construir contenedores suficientemente protectores y defensivos de la identidad propia. A veces hay necesidad de descubrir y, al mismo tiempo, de no dejarse conocer enteramente (sea en los jóvenes, sea en los adultos). Me refiero al impacto que las nuevas generaciones pueden tener con el Instituto en el momento del ingreso o en las primeras fases de la formación inicial y de la inserción en una nueva cultura, es decir, en un nuevo modo de pensar, de relacionarse y de obrar, en un nuevo estilo de vida.

En la experiencia gradual de elaboración y reapropiación de la identidad, son tres los referentes mayormente implicados y que, en todo caso, hay que salvaguardar: el espacio geográfico, el espacio corpóreo y el lingüístico, como por lo demás sucede con el niño en quien las modificaciones en el espacio se mueven precisamente en estos tres ámbitos:

-el espacio geográfico donde se inscribe el espacio ambiental, sobre todo el familiar, con sus simbolizaciones e imaginaciones;

-el espacio del cuerpo que corresponde a la experiencia del sí corpóreo. Toda cultura posee su propia modalidad de concebir el espacio corpóreo, las fronteras de la intimidad, las condiciones de la conversación, las maneras de recibir, de comer, de cuidar la higiene del propio cuerpo: ésta es una dimensión muy profunda, difícil de modificar y elaborar;

-el espacio lingüístico que, además de la lengua, comprende también cada uno de los sistemas de comunicación no verbales, los mundos vitales y de significado.

Cada itinerario formativo tendrá que tomar en consideración la necesidad de salvaguardar estos tres espacios, con vistas a favorecer un correcto proceso de individuación y de reelaboración de la identidad individual y cultural de cada persona.

Los diversos cambios en la identidad personal que se realizan en concomitancia con la asunción de la identidad vocacional carismática tienen como presupuesto básico las modificaciones típicas de estos tres espacios. Si no son respetados, pueden brotar alteraciones de la identidad no siempre fácilmente reconocibles como tales. Pensemos, por ejemplo, en sentimientos de frustración, de inadecuación o de inferioridad provenientes de la no comprensión de las exigencias lingüísticas o geográficas, ligadas a menudo a prejuicios y estereotipos raciales o nacionalistas. Así, la falta de atención al espacio corpóreo puede 
hallarse en el origen de problemas que afectan sobre todo a la esfera emocional, afectiva y sexual, además de las alteraciones de la esfera alimentaria, como la anorexia o la bulimia.

\section{IDENTIDAD Y VOCACIÓN}

\section{1. ¿Qué vocación?}

La reflexión teológica, a partir del Vaticano II, ha mostrado el carácter dialógico-relacional y dinámico de la vocación, no sólo del hombre con Dios, sino del hombre consigo mismo, con los demás, con la Iglesia, la sociedad y la cultura.

Hablar de 'vocación' significa, sobre todo, hacer una esencial referencia a Dios, aunque en ella se contempla también necesariamente la respuesta de la persona. En efecto, toda vocación es siempre una historia de inefable diálogo entre Dios y el hombre, entre el amor de Dios que llama y la libertad del hombre que responde ${ }^{17}$. La llamada de Dios está unida con una respuesta personal e histórica: es llamada y respuesta; mejor, «la respuesta personal es parte integrante de la consagración religiosa ${ }^{18}$. En ese sentido, implica la construcción de la persona, porque la respuesta a Dios que llama se mezcla con aquel largo iter de crecimiento y de formación que nos hace hombres y mujeres maduros.

Por eso, hay que entender la vocación como un desarrollo dinámico y como un proyecto que gradualmente se va descubriendo y elaborando en armonía con la propia identidad. En esta perspectiva se comprende la estrecha correlación entre respuesta vocacional y sano funcionamiento de la personalidad, entre identidad vocacional e identidad personal. La llamada de Dios se dirige a una creatura que es tomada en la totalidad de sus recursos actuales y potenciales y en todos sus dinamismos.

No se puede plantear ningún itinerario formativo si no se parte de la realidad de la persona que, con su peculiar identidad y proyecto personal, se identifica con la identidad y el proyecto del Instituto definido por el carisma.

\section{Identidad y proyecto vocacional}

El proceso de crecimiento vocacional se injerta con el camino de maduración e integración de la persona. El devenir vocacional procede al mismo paso que la formación de la identidad personal y cultural, se entrelaza con todas las vicisitudes, las dificultades y las crisis que tal crecimiento conlleva. El proyecto vocacional se desarrolla en conexión con la definición de sí y el proyecto de sí,

17. Cf. Pastores dabo vobis. Exhortación de Juan Pablo II sobre la formación de los sacerdotes, 25 de marzo de 1992, 36 [= PdV].

18. Congregación para los Institutos de Vida Consagrada y las Sociedades de Vida Apostólica. Directivas sobre la Formación en los Institutos religiosos 1990, 9 [= PI]. 
y depende, especialmente durante la adolescencia, de las identificaciones con personas, comunidades, ambientes y propuestas de vida que sirven de modelos de referencia para llegar a hacer una opción que resulte coherente con el propio proyecto de vida.

Identidad y proyecto vocacional son, pues, dos coordinadas estrechamente vinculadas e interdependientes una de otra. En esta óptica, se comprende cómo tantos proyectos vocacionales no maduran, quizá mueren antes de nacer, y también el por qué de tanto escepticismo en relación con la posibilidad misma de identificación vocacional por parte de los jóvenes. Así se explica el fenómeno de la denominada consagración débil, es decir, de la incapacidad de una duradera fidelidad de compromiso religioso. De hecho, no es raro encontrar personas en las que el proyecto vocacional se construye sobre un «vacío de identidad», y eso es problemático para la perseverancia religiosa ${ }^{19}$.

Por lo demás, la vocación es una realidad de carácter dinámico e histórico, que se inserta en el proceso evolutivo y de maduración de la personalidad; asimismo, se desarrolla y se consolida en el tiempo y en un determinado contexto humano y social-relacional. La llamada gratuita y misteriosa de Dios acontece por norma general a través de una serie de mediaciones, tanto individuales como comunitarias y sociales, de manera que la vocación permanece sometida a los diferentes condicionamientos personales o socioculturales, y se desarrolla en relación con los retos y con las llamadas del contexto, de la historia y de la cultura en que vive.

El camino para alcanzar plenitud de identidad vocacional sigue siendo siempre el de asumir de forma madura las posibles dificultades o condicionamientos de una sociedad que cambia, sin miedo de afrontar el cambio, seguros de que la identidad se consolida, en lugar de perderse, si se permanece en actitud de apertura y de búsqueda constantes.

\section{La dinámica de la identidad personal en el proceso de crecimiento vocacional}

Toda vocación, en cuanto proceso dinámico de crecimiento, se desarrolla en el contexto de la vida y la maduración de cada persona. Los estadios del crecimiento humano (las etapas de la vida) coinciden con el crecimiento vocacional, con frecuencia ponen de manifiesto su vitalidad, pero también pueden ralentizar su ritmo evolutivo. Por eso se supone que se han alcanzado las metas evolutivas esenciales para hacerse "adultos» y se han realizado las tareas de desarrollo propias de cada edad de la vida.

Por consiguiente, la formación tiene que ver con este proceso de crecimiento y de maduración que se realiza mientras la persona responde a la llamada de

19. Cf. Del Core, P., Dimensioni e articolazioni dell'identità nel suo processo di maturazione, en Del Core, P. - Cavaglia, P. (eds.), Un progetto di vita per l'educazione della donna. Contributi sull'identità educativa delle Figlie di Maria Ausiliatrice, Roma 1994, 39-53. 
Dios: un proceso de unificación personal y de construcción de una identidad (cf. PI 6; VC 65) que se realiza a través de algunos pasos fundamentales que señalamos a continuación:

a) Redefinir la propia identidad personal y cultural. En el camino de construcción de la propia identidad vocacional carismática es necesario, ante todo, un proceso de consolidación de la propia identidad personal y cultural. El joven que entra en el Instituto lleva consigo un equipaje de experiencias y de motivaciones que se refieren substancialmente a una identidad personal y cultural ya delineada. En el impacto con nuevas identidades se trata, pues, de redefinir la propia identidad; se supone que la persona tiene ya una cierta definición de sí misma, es decir, que ha respondido a la pregunta fundamental ¿quién soy yo? y ha alcanzado una cierta estabilidad (no se está poniendo constantemente en tela de juicio y no cambia identidad en cada ambiente, relación o situación en que se llega a encontrar).

b) Comprobar y consolidar la identidad vocacional. La identidad personal llega a su madurez cuando la persona se hace capaz de relaciones maduras y a tomar una opción de vida estable y una opción de valores significativos; de forma que el descubrimiento de la propia vocación y la progresiva certeza de la llamada completan la formación de la identidad. Responder a las preguntas: ¿Qué sentido tiene mi vida? ¿En qué dirección debo orientar mi existencia? ¿Por quién y por qué empeñar mis energías? lleva a la persona a descubrir su propia vocación (¿Qué quiere Dios de mí?) y, por consiguiente, a adquirir una nueva identidad, «la identidad vocacional».

En el tiempo de la formación inicial, la identidad vocacional se consolida progresivamente hasta que la persona llega a la certeza interior de ser llamada por Dios, a la conciencia de que ésta es verdaderamente la opción que da sentido a su vida.

c) Asumir gradualmente en la propia personalidad los rasgos de la identidad carismática. La llamada de Dios alcanza a la persona en su concreción histórica, en sus disposiciones y aptitudes humanas. Si es verdad que la persona se unifica interiormente llegando a ser cada vez más ella misma (identidad personal) según lo que está llamada a ser (identidad vocacional), es igualmente verdad que todo esto no se realiza en abstracto, sino dentro de un recorrido de conocimiento y de asimilación de una vocación específica y «dentro de» un peculiar carisma (identidad carismática).

Entonces, la «identidad carismática» llega a ser una meta evolutiva de crecimiento que, no obstante, necesita un itinerario estudiado, etapas y metas intermedias articuladas en una lógica de progresión. En primer lugar es importante preguntarse qué es la identidad carismática para, a continuación, determinar sus recorridos de formación. Se la puede describir como una identidad que se construye sobre la base de los valores y de los ideales expresados por el caris- 
ma del Instituto. No existe como realidad independiente, es decir, separada de la persona que la vive. El carisma, como don del Espíritu, tiene una consistencia objetiva propia, pero se hace visible y concreto cuando se encarna en las personas, en las estructuras, en las obras y en proyectos concretos. La identidad carismática es tal, solamente si se refiere al carisma y se estructura en torno a los valores vocacionales del carisma. Por eso, cada uno debe integrar en su identidad personal los valores, las opciones y las indicaciones carismáticas implícitas en la vocación a la que se siente llamado. Este camino no es fácil, ni automático: conlleva el esfuerzo de una asunción gradual realizada a nivel personal en la experiencia diaria, exige una reestructuración de actitudes y de comportamientos que no siempre está exenta de conflictos y de dolor.

d) Progresivas reestructuraciones de la identidad en el transcurso de la vida. Crecer en la identidad debe ser una preocupación constante, que pide una formación continua y permanente. Frecuentemente se observan paradas de la identidad, tanto en la segunda como en la tercera edad, precisamente cuando uno se encuentra en el momento de tener que asumir una nueva perspectiva de la existencia, especialmente en relación con los varios cambios (culturales y otros). Esto implica el abandono, si no ya una ruptura, de las precedentes «identidades para integrar las nuevas estructuras y relaciones provenientes de la nueva situación. Esto provoca una verdadera y auténtica crisis, porque la persona debe pasar por la dolorosa experiencia de reestructuración, con todo el malestar y la ansiedad que conlleva. De otra forma, si no se logra jugarse la propia realidad personal «nueva» consigo mismo, con los jóvenes y después con todos los demás, se corre el peligro de entumecerse y de empobrecerse en el plano personal, hasta llegar a formas de inadaptación, de depresión y/o enajenación.

Confrontarse con «el archipiélago de nuestras numerosas identidades distribuidas en el transcurso del tiempo ${ }^{20}$ se convierte en un recorrido obligatorio, en cuanto que pide procesos de conciencia de sí y de reconciliación, que después desembocan en la unificación de sí.

Si no nos medimos con las diversas «identidades» requeridas por las diversas edades de la vida, el camino de crecimiento en la identidad se obstruye, pero también la vocación se queda abarquillada y frenada, en cierto modo. Signos evidentes de ello son: el infantilismo, la hiperactividad y la consiguiente depresión por estrés, el protagonismo individualista, etc., de los que brotan una serie de dificultades en el plano personal y, sobre todo, comunitario. En esta perspectiva muchas crisis vocacionales en la segunda o tercera edad hay que interpretarlas como paradas de crecimiento de la identidad.

20. Puede verse a este respecto Demetrio, D., Raccontarsi. L'autobiografia come cura di se, Milano 1996, 34. 


\section{RECORRIDOS DE CRECIMIENTO PERSONAL}

La formación de la identidad vocacional se realiza mediante itinerarios formativos que se articulan fundamentalmente a lo largo de tres áreas estrechamente unidas entre sí: el área de la identidad personal y cultural, el área del crecimiento en la fe, el área de la misión y de la espiritualidad propia del carisma.

Mirando, en especial, el área de la identidad personal y cultural se puede evidenciar algunos recorridos de reapropiación específicos.

a) Progresiva toma de conciencia de la propia identidad cultural y personal. La reapropiación de la identidad se produce mediante la progresiva conciencia de la propia identidad personal y cultural. Y eso no sólo a nivel cognitivo, sino sobre todo a nivel emotivo-afectivo (las vivencias, las experiencias, las resonancias, la memoria), relacional y social.

Quien desarrolla esta conciencia adquiere una fuerza de proyección y de apertura a los demás y a las culturas, que hace posible una interacción desde la serenidad y la libertad. La persona encuentra más fácil vivir en el respeto de las diversidades de cultura, de edad y de formación, y asimismo se siente impulsada a descubrir sus valores o a buscar su raíz común, sin creerse por ello disminuida o inferiorizada.

Hay que conceder especial atención a la simbolización de las experiencias, es decir, al grado de elaboración cognitiva y de conciencia vivida y refleja de sí mismos y de las propias experiencias, de los hechos y de los acontecimientos, de los símbolos y de los códigos de la cultura propia. Ese proceso exige la maduración de un pensamiento lógico formal, que capacita a la persona para ir más allá de lo inmediato, de lo concreto y de lo visible, para captar en profundidad el núcleo de sentido escondido en cada experiencia y unirlo mediante un hilo conductor al conjunto de la vida y de la historia. Presupone un recorrido de conocimiento objetivo de la historia y cultura propia, incluso mediante el estudio y la profundización intelectual.

b) Aceptación de la historia propia. Un segundo recorrido obligatorio lo ofrece la aceptación de la historia propia, es decir, de los hechos vividos, de las personas encontradas, de las relaciones, de las experiencias, de los problemas resueltos; pero, sobre todo, de los significados y reflexiones hechas sobre ellos. Efectivamente, «la identidad se corresponde con la aceptación de todo lo que nos ha sucedido: de todo lo que hemos incluido o excluido, de lo que hemos llegado a ser o de ninguna forma hemos llegado a ser, de aquel poco que hemos afrontado en el intento de encontrar una trayectoria existencial suficientemente concatenada a razones prácticas o ideales, o bien, a aquel mucho que no hemos logrado ni coordinar en modo alguno, ni retener para siempre, ni racionalizar a nuestro gusto ${ }^{21}$.

21. Ibid., 73. 
c) Aprender a hablar y escribir de sí (autobiografía). La experiencia de sí y de la individualidad propia se construye y se consolida ya en la adolescencia por la capacidad de reflexionar y que, sin embargo, tiene necesidad de salir del riesgo de encerrarse emotivamente dentro de sí mismo (introspección «salvaje») a través de la narración de sí, en el marco de una historia. La identidad, en efecto, puede encontrar consistencia por parte de la historia que narra, hace revivir y modifica según las diversas experiencias.

La narración autobiográfica puede convertirse en un espacio de crecimiento, donde la unidad de la narración lleva a la unidad de la identidad incluso en la multiplicidad de las experiencias que componen nuestra vida. Aprender a hablar y escribir de sí es como emprender un "viaje formativo», en el que se reviven más profundamente aquellas experiencias, aunque no sean positivas del todo, que han constituido la trama de nuestra vida. Es un reconfirmar y, al mismo tiempo, un reelaborar vivencias, hechos y acontecimientos a la luz de un nuevo sentido de la vida. Ese camino en la edad adulta puede llegar a ser verdadero camino de autoformación y de cuidado de sí.

En estos recorridos de reapropiación es importante prestar atención a algunas instancias, que pueden formularse así:

-cómo seguir siendo nosotros mismos e idénticos a nosotros mismos (un núcleo interior que permanece en el tiempo), pese a los múltiples cambios externos e internos, personales y ambientales;

-cómo ser nosotros mismos con las características y las cualidades propias que nos distinguen de los demás (proprium), pero también mediante la integración de los caracteres comunes a otras cosas o personas y en un conjunto integrado por componentes y elementos diversos (unidad);

-cómo llegar a ser cada vez más nosotros mismos asumiendo los rasgos y valores de la identidad vocacional-carismática (identificación con Cristo y con el carisma, pero también con los roles y los cometidos relativos a la misión del Instituto y a la organización comunitaria) por la realización de la llamada de Dios y de su proyecto de salvación.

\section{CONCLUSIÓN}

Dada la complejidad y la amplitud del tema, son muchos los problemas y las perspectivas que permanecen abiertas. Por consiguiente, es menester ponerse a buscar mediante un riguroso discernimiento a la luz del Espíritu, ahora ya más conscientes de la necesidad de redefinir y de cualificar la formación con un esfuerzo proyectivo que requiere una visión lo más amplia posible de las fuertes dinámicas de cambio que atraviesan la sociedad y la cultura y que inciden profundamente en las identidades, de las personas y de las instituciones, especialmente las educativas. 
Quiero indicar al menos dos pistas de camino que me parece que deben ser privilegiadas simultáneamente.

-Un camino individual, mediante la activación de un constante y consciente proceso de autoformación, en un itinerario de progresivo conocimiento y aceptación de sí, de la historia personal propia, de integración de las diversas dimensiones del propio ser (afectividad, sexualidad, racionalidad, agresividad, religiosidad), de las múltiples, fragmentadas experiencias vividas y sobre todo de las exigencias, problemáticas y necesidades propias de toda estación de la vida que se atraviesa, de reapropiación de la identidad cultural propia.

-Un camino comunitario, en el que formación de la persona y de la comunidad se realizan simultáneamente en una mutua interacción, en la coparticipación del trabajo, del servicio y de la riqueza espiritual personal. La comunidad, lugar de formación en la diversidad y reciprocidad, es necesaria para crecer en la identidad personal, cultural y vocacional; pero debe comprometerse en algunos pasos:

-Cambio de mentalidad, acogida y apertura a la diversidad.

-Conocimiento de los elementos esenciales de los jóvenes y de la cultura de los formandos.

- Conversión continua a Dios presente en cada persona y en cada cultura.

-Educar y educarse en la reciprocidad.

-Crear un clima intensamente evangélico partiendo de la experiencia de la paternidad de Dios para llegar a la fraternidad y al perdón mutuo. 